\title{
The Two-Factor (Authority-Solidarity) Model of Society's Structural Cycles in the Evolutionary Perspective
}

\author{
Sergey V. Dobrolyubov \\ International Center for Education and Social and \\ Humanitarian Studies, Moscow
}

\begin{abstract}
The two-factor model of social dynamics describes the rise and decline of political integrity and collective solidarity of different scales. The model takes into account two factors of change-social authority and collective solidarity, and considers two structural entities that embody these factors - political organization and society itself. For the analytical distinction between power and society, the model uses general concepts of a collective agent and a collective subject. A collective agent is any organized group of people who carry out collective actions through the use of social power. It is an active social entity and an agent of intentional social transformations. Collective subject is a commonality that carries collective self-awareness and solidarity. It is an inertial and unintentional social entity that preserves social tradition, culture, collective identity and etc. Political and societal entity effects on each other with time lag and this gives a cyclical pattern to the dynamics of the entire socio-political structure. The model can be used for explanatory and forecasting purposes, and also for reconciliation of the unilinear (progressive) and multilinear (nondirectional, cyclical, etc.) evolutionary concepts. Finally, an interpretation of the structural transformations of Ancient Rus and Russia is given in terms of the model.
\end{abstract}

Keywords: social evolution, society life cycle, Ancient Rus, Russian nation, Eurasian Civilization, sociogenesis, social dynamics, structural transformations.

Social Evolution \& History, Vol. 20 No. 1, March 2021 65-93

(C) 2021 'Uchitel' Publishing House

DOI: $10.30884 / \mathrm{seh} / 2021.01 .03$ 


\section{INTRODUCTION}

Process modeling is the most effective method of scientific description and forecasting of social dynamics. Mathematical modeling of historical and evolutionary trends is developing within various interdisciplinary approaches (see e.g., Grinin, de Munck, and Korotayev 2006; Grinin, Korotayev, and Herrmann 2010; Korotayev, Malkov, and Khaltourina 2006; Turchin et al. 2006; Turchin and Nefedov 2009; Turchin 2003). Meanwhile, the mathematical expression itself is just a formula that requires a conceptual model of the phenomenon underlying the detected trend; only then the formula acquires an explanatory meaning. The model proposed here is such an explanatory theoretical concept which is supposed to precede a quantitative analysis of periods, stages, etc.

Before considering the model, I would like to make preliminary comments about the model and the concepts of social format and phases of sociogenesis that I use.

\section{The Novelty of the Approach}

The model has evolutionary explanatory potential and allows us to reconcile progressive and cyclical development of society. Indeed, on the one hand, society 'in general' becomes more complex in the course of evolution, but on the other hand, particular societies rise and fall (Diamond 2005). These falls undermine the concepts of linear or progressive evolution. Neo-evolutionism, under the pressure of particular case studies, has gone away from Herbert Spencer's concept of unilinear evolution directed towards increasing society complexity (White 1949; Carneiro 1970) to the concept of multilinearity (Steward 1955; Bondarenko, Grinin, and Korotayev 2002) and division of evolution into specific and general one (Sahlins and Service 1960) and, finally, to the concept of evolution as any qualitative transformation (Claessen 2006). Our model points out one of the reasons (without rejecting others) for the collapse of societies, namely, their inability to form an overly broad cohesive social subject along with the natural decline of the collective solidarity of any compact society. In this case, the decline of core collective solidarity leads to the collapse of the entire political structure. This forms the society's life cycle, which can be considered within evolutionary scheme as an analogue of the life cycle of an organism in natural evolution. Recurrent structural cycles of societies' growth and decay (life cycles) become possible without transition to a new stadial level. In its turn, the gradual accumulation of changes over a number of cycles can help a society to make such a transition in ordinary cycle of its structural growth. 


\section{The Model}

This model is not related directly to the theories of politogenesis and the early state (ES) origin, which are usually discussed on the pages of Social Evolution \& History journal. The model describes social dynamics in a different context - it is the model of the growing scale of a socio-political entity, and not of its evolutionary stadial transformations. Of course, there may be a correlation between the scale and stadial dynamics, but so far we are interested in the very mechanism of extension of socio-political entities, purified from the influence of other factors.

Nevertheless, the proposed model is an implicit evolutionary concept, since in the course of social evolution people start to integrate into ever larger societies. This model refers to the structural phase of social evolution (Dobrolyubov 2020), which started with the Neolithic transformation of gatherers/hunters bands into village communities and will continue till a single and equilibrium global society emerges.

The model considers growth (enlargement, extension, and expansion) of a political entity as a natural tendency due to the phenomenon of social power and the competitive nature of human collectives. Obviously, every society is hardly able to succeed in this competitive process. So, the model is not the law of growth for each particular society, but a pattern that actually characterizes the 'winners,' for example, like the successful political entities of Early Egypt, Mesopotamia, Rome, Muscovy and etc.

There are many reasons why some societies appear stronger and more successful than others. The contributing factors may include better location, political or military organization, better economy, ideology, laws, decisions, chosen strategies and so on ... and, finally, a combination of circumstances. Our model considers only one source of a society's high (or low) competitiveness - its internal solidarity ensured by common social values. The collectivization of people into ever larger cohesive societies is also considered within our model as a natural tendency caused by human social needs which are the flip side of the need for group competition - the need to band together with other people, the need for solidarity and cooperation within society.

Accordingly, the model focuses on two factors of changes - organized authority and collective solidarity. To analyze their mutual dynamics over time, we distinguish between political power and society proper. Obviously, in early societies we can only analytically separate power from society, since they do not have political power in the ex- 
plicit form of a distinct administration and, even to a lesser extent, do they have a professional apparatus (Grinin 2008; Bondarenko 2014). To make this distinction, we use more general concepts of a collective agent and collective subject (Dobrolyubov 2012c), of which the authority organization and society are special cases.

A collective agent is any organized group that performs coordinated (i.e. collective) actions. An indicator of a collective agent is the use of social power over individuals in order to organize group activities. A collective subject is a self-aware collectivity, united by common values of individuals and, most importantly, by the shared value of their own community. The attributes of a collective subject are social (collective) consciousness, strong collective identity and group cohesion.

This approach allows us to describe the same social object from two different prospectives. When an individual acts in an organized manner with others (works, hunts, or fights) he actualizes the feature of the collective agent, but when the same individual perceives (is aware, feels, and values) his commonality with others, he actualizes the feature of the collective (social) subject. We can make this distinction even for a band of gatherers and hunters. A band can be considered as a collective agent when its members follow their leaders and act in an organized manner, and can be considered as a social subject when its members show agreement of opinions, unanimity and solidarity. Such an analysis does little for bands, but in the case of societies capable for growth, we can separately consider the extension of political organization of the 'collective agent' (as a result of conquest, subordination, control, etc.) and the formation of a solidary society or 'social subject' within these political boundaries (as a result of changing consciousness). So, in fact we separate two processes - organization (administrative, authoritative, political) and value (mental and societal).

\section{Societal and Dimensional Formats}

An important point of our model is the distinction between the scale and stadial aspects of the societal format notion. The societal format in the early state theory is a qualitative type of social structure (Claessen and Skalník 1978). However, this type implicitly contains a scale component, since a society at a higher evolutionary stage of development, as a rule, possesses a broader scale. This is more obvious at the beginning of the stadial sequence: band - settlement - chiefdom - complex chiefdom, where every subsequent type of society includes several societies of the previous type. For example, chiefdom consists of several settlements, and a complex chiefdom consists of several chiefdoms 
(the same for their analogues and alternatives). In the state societies, we no longer observe such a rigid link between the type of society and its scale and such a hierarchical inclusion of the previous type structures into the subsequent ones. Therefore, the scale aspect is not in the focus of the early state theory, and even more so of the theories of modern societies transformation, for example, modernization theories, Marxism, etc. ${ }^{1}$ Our model, on the contrary, considers the scale of socio-political entity and offers its end-to-end dimensional typology. Therefore, we exclude from consideration all other stadial characteristic that describe society as an early, developed or modern state.

In essence, the dynamics of all societies, including modern ones, demonstrate a similar aspect of transformation as the transition from chiefdom to complex chiefdom, namely, the hierarchical inclusion of earlier formats within the subsequent ones. To demonstrate this, we use the notion of a dimensional format (or scale format) of sociopolitical entity instead of a societal format that rather indicates the stage of evolutionary development.

The dimensional format is not so much a territorial size, but the measure of internal diversity of a socio-political entity. In our model there are dimensional formats that succeed the complex chiefdom; and the socio-political structure in each subsequent format includes several structures of the previous formats. We define the polis, territorial, national, civilizational and global formats. Of course, these dimensional types may or may not coincide with stadial types. ${ }^{2}$ In our model, the dimensional types only formally make a sequence of growing formats that do not correlate strictly with the evolutionary stages of societal development. The model implies both the growth of a political entity from a small city polis (polis format) to a large empire (civilizational format) without a transition to statehood, and vice versa, a transition of society to the next stage of evolutionary development within the same dimensional format.

Thus, the model takes into account indirect indicator of social complexity - a greater social heterogeneity in wider formats. Each subsequent dimensional format, by definition, includes greater societal, cultural, ethnic and religious diversity. The transition of the political entity to a wider format is associated with the inclusion of some external components. This undermines the traditional collective identity of the core society and requires some time to smooth the differences in the 'melting pot' of a broader political system and to unify the expanded society. Consequently, the formation of collective identity and 
solidarity and the time parameter - the period of their formation - are introduced as variables in the model.

The dimensional transformation of socio-political structure passes through two main successive stages (phases) - administrative and universal, which are characterize by a different state of a society within a given political framework.

\section{About Phases}

At the administrative phase, the political structure expands through incorporation of various socio-political objects. This may happen via cooperation and voluntary integration, as well as through subordination and warfare. The new power structure establishes common social and economic practices, so there starts the process of smoothing out differences and convergence of values (often in the simple form of assimilation). The political agents exercising social power are the main factor of changes at this phase. Social power can be used with varying degrees of totality and rigidity, from a limited to full control over individual's life, from charismatic guidance to coercion or even genocide of the defeated population.

At the universal phase, the population within these political frameworks acquires a common social identity, common value system and, thus, group cohesion. Now, it is a society that has its own subjectivity. The society becomes a subject that all collective agents have to take into account. Political agents (authority, elites, army, etc.) relying on the solidarity of its social core begin to compete in a wider format; and the two-phase step of political framework expansion and formation of a wider social core can be repeated. However, this assumes decomposition of collective subject and solidarity of the previous format.

The interaction between these two processes and the alternation of the administrative and universal phases make up the mechanism which is described by our two-factor (authority-solidarity) model. We found out that the maturation of collective self-awareness and solidarity takes about 200-300 years in all types of societies (Dobrolyubov 2009). This 'quantum' of structural changes determines the entire time scheme and prognostic capabilities of the model.

The presented paper provides an analysis of dimensional (it bears repeating that not stadial) transformations of Ancient Rus, and then Russia. This is not a historical research but an interpretation of famous events in terms of the model, which, nevertheless, adds new explanatory aspects to understanding of the past and modern integration/disintegration processes. 


\section{A Methodological Note}

Political anthropology has made significant progress in the study of early political systems formation and seeks to involve all the factors in consideration in order to create the most complete models of social transformations (Carneiro 1970, 2012; Claessen 2002, 2006, 2016; Claessen and Skalník 1978; Claessen, van de Velde and Smith 1985; Grinin 2008; Grinin et al. 2004; Bondarenko 2008, 2014; Bondarenko, Grinin and Korotayev 2002).

Meanwhile, the multi-dimensional evolutionary models have one methodological drawback: they tend to consider the impact of different factors independently from each other. This is a common way of analytical idealization of complex transformation in order to reveal a causal link between a factor and its evolutionary outcome. This way, we may lose the sight of the second-order factor - the mutual influence of factors. The impact of factors combination turns out to be specific for each historical case, and as a result, a proper explanatory model does not work properly.

I propose here a slightly different methodological approach. Let us limit ourselves to considering only two factors (in our case, organized authority and collective solidarity), and first try to build a model of their interaction, leaving the evolutionary outcome aside for a while. What can this give us? It may allow us to include the obtained two-factorial mechanism as a single factor into a more complex context; but now we greatly simplify its complexity.

\section{A SIMPLE MODEL OF STRUCTURAL CYCLE}

\section{Collective Agents and Collective Subjects}

Authority and solidarity are ultimately embodied in social structures. Regardless of how classical sociology understands social structures whether in the form of real entities or concepts in mind (see, e.g., Durkheim 1964; Mead 1934; Parsons 1971; Giddens 1984), we will adhere to two simple criteria for structuring - external and internal for an individual, which correspond to our factors and lead to different types of structures, no matter how sociology define them.

External (authoritative) structuring occurs through the organization of individuals with the help of social power over them. Internal (mental) structuring occurs through the typification of individuals' minds, which is manifested in the similarity of their ideas, values, intentions, motives, attainments, culture, etc. Accordingly, two types of structures are formed: collective agents as organized group actors and 
collective subjects as typically conscious commonalities (Dobrolyubov 2012c). They have different structural genesis and properties.

Collective agents are organizations such as economic enterprises, political parties, armies, gangs, acting groups, governmental agencies, including whole states. Collective agents perform collective actions using social power of leaders (chiefs, kings, bosses, managers, bureaucrats, etc.) over members of organization in any type of authority described by Max Weber - charismatic, traditional or legal (Weber 1978). The group actions of organized individuals are intentional and rational, and their social outcome is open, non-deterministic.

Collective subjects are solidary communities, such as comradeships, brotherhoods, interest clubs and cohesive communities of various sizes, including the widest community - the society. They arise from the standardization of values and practices that occurs in the area of communication. They possess common collective consciousness (Durkheim 1964), group's self-awareness and solidarity.

In fact, many real social entities (clans, sport teams, fan clubs, religious entities, gangs, etc.) combine group organization and group solidarity which, nevertheless, one can analytically distinguish. State society is also an inseparable social whole; but it is obvious that state and society is not the same thing (Claessen 2002; Grinin 2008; Bondarenko 2014). That is why we have to analytically divide the socio-political structure (organization, system, etc.) into societal and political ones in order to analyze how these phenomena of a mental and administrative nature affect each other.

\section{The Political Organization as a Collective Agent}

Collective actions are organized or coordinated actions of potentially independent individuals. Group actions are organized through the application of social power over participants, even if the latter act voluntarily, have common goals and seek to cooperate. Coordination itself is the application of power. Personal charisma and even intellectual attractiveness of someone's ideas are also the forms of application of social power over an individual. The subordination to power (in fact, predominantly voluntary) is the flip side of power application; the latter is impossible without the former. ${ }^{3}$ That is why most of organizations, including the voluntary ones, have a hierarchy of decisions, in which decisions made at one level are transmitted to a lower level and executed. Only due to the use of leaders' power an organized group may act as a single agent - rationally and intentionally. 
Thus, social power is the source of organization. Organizations appear constantly and everywhere; it is as natural process as natural social power itself. ${ }^{4}$ There are just evolutionary limitations for the extension and complication of political organizational structure.

Institutionalization of organization. Organizations can be explicit, permanent and expressed in formal institutions, like political parties, armies, governmental bodies etc. However, organization can be implicit, situational and informal, as in the case of collective hunting, friendly fests, crowd manipulation, etc.

The institutionalization of organization is a transformation of temporal hierarchy of individuals subordinate to the leader's charismatic power into a permanent hierarchy of power positions. The leader of a new organization usually uses charismatic authority at the initial stage of development of the organization. Such organizations, for example, the elite's organization, may monopolize activities related to the whole community - sacral, ritual, defensive, judicial etc. The recurrent execution of power and longtime existence of the organization leads to what Weber called the 'routinization' of charisma (Weber 1978), that is to traditionalization and institutionalization of the organization in the form of permanent positions with roles, rules, ethic, ideology, etc. Then power becomes a function attributed to the position. Whoever takes the position acquires the power of this position regardless of personal charisma. Now this power becomes legal or traditional.

However, power is only assigned to the position. In fact, the person occupying the position uses the power. The actor can be restricted by the function or role of the position, nevertheless it is the actor (not the role or function) who decides what political decision should be made, whether to start or not a war, whether the police should arrest criminal or not. In this regard, the political organization not only functionally regulates (maintains) social relations but also acts as an agent who may make decisions potentially deregulatory and even fatal for society. Therefore, to analyze the transformations of political entity, we will consider the political organization as an active collective agent, and not as a systemic regulator. ${ }^{5}$

For our model, it is important that the power organization exists not only in state societies, but also in pre-state societies, although in less distinct and less formal form. ${ }^{6}$

\section{Society as a Collective Social Subject}

A society is not only a population under political control, nor just an area of shared language, culture, religion, etc. It is also a social whole that is collectively aware of itself and has collective solidarity. 
Common ideas and practices give rise to informal integrity. The standardization of individual consciousness is a natural and rather 'technological' process, since a human being acquires consciousness via communication with other human beings also possessing consciousness, by adopting the content. Therefore, a symbolic unification happens in the area of human communication, including common language, knowledge, values, culture, etc.

Consciousness acquired by the individual is not only standard in content, but is also steadily oriented by his value motivation. A person cannot arbitrarily change his already established value orientation. This follows from the mechanism of formation of abilities, which consists in reinforcement of repeated practices. People may operate by any ideas and set any rational goals, but as soon as they begin to repeatedly practice them, they do acquire non-rational attachment to them, which is expressed as a motive (Dobrolyubov 2013).

Values as mental motives. Values are not just true rational ideas but convictions; they are ideas to which a person has formed a mental addiction during previous practice. In other words, values are needs that should be satisfied and, thus, they are motives that guide further activity. However, theories of motivation (e.g., Maslow 1943) can be hardly applied to collective value system or, at least, must be adapted to it, because collective phenomena differ from individual ones.

Collective consciousness. The concept of 'collective consciousness' as a set of common ideas, introduced by Emile Durkheim (Durkheim 1964), is sufficient for our model to take into account typical consciousness and behavior, ${ }^{7}$ although there are more specific sociological (e.g., collective thinking [Mannheim 1936]) and even psychological concepts (e.g., archetypes of the collective unconscious [Jung 1991]). One can also mention the medieval concept of collective solidarity - asabiyah (Ibn Khaldūn 1958). In our model, collective or Social Consciousness is just a typical or shared part of individual consciousness, regardless of whether these ideas and motives are social or of any other kind, whether they were formed by rigid traditional institutions or by modern values and practices. The only criterion of 'social' is typicality. Thus, unique, unusual, and not widespread ideas are not included into the social consciousness. In their turn the simplest, most basic, and most shared ideas and mental motives form the socalled Mass Consciousness.

Collective self-awareness. However, this is only one side of this collective phenomenon. Once the individuals' sameness is manifested, 
they begin to reflect on it. The repeated practice of reflection on the sameness with others forms relevant ideas and motives, that is a value of this sameness, value of this association of people, and value of this collective identity. As a result, the social consciousness acquires a typical perception in society and attitude to it. We denote this as a collective self-awareness or society's self-consciousness. This is a mass value perception of one's own society.

Collective (social) system of values. The combination of formation of motives with standardization of ideas has a simple consequence which was ignored by theories of motivation (Maslow 1943). Collective consciousness comprises its own hierarchy of values different from any individual hierarchy, because it is built on a different foundation. Social consciousness contains the most shared values rather than the ones of top priority for individuals. It ignores the individuals' unique egoism but accounts the value of the most common objects; and the society is the most common one. As a result, the social hierarchy of values (national, polis, etc.) has the value of the society itself as a top priority of this value system. Collectivity with such selfish group awareness becomes the Social Subject aimed at achieving common goals and, above all, at the self-preservation of the community. An individual is always aware of this group identity; he opposes his group self (Tajfel and Turner 1986) to other groups as he opposes his personal self to other individuals. Social subject is always selfish and competitive.

The society can be defined as the broadest among the collective subjects that is as a social entity possessing the broadest system of values with the value of this particular social whole as a top priority. That is why all true societies are self-sufficient (Parsons 1971). Broader collective identities (up to the whole humanity) are only descriptive concepts. They do not form their own value system and, therefore, they are not social subjects. The recognition of one's own society is the Main Social Identity (MS identity) of individuals (Dobrolyubov 2009). The formation of social subject and its MS identity is a timeconsuming (historical) process; thus, this identity can be strong or weak. MS identity is both an individual and a collective phenomenon; and individuals acquire this identity in the same way as they acquire language, culture, etc.

The 'behavior' of a social subject is expressed through typical individual intentions and actions. Despite the fact that all widespread ideas are rational, no particular individual affects their typicality; therefore, society's 'choice' is unintentional and non-rational. Society rather has a 
trend due to the influence of mass consciousness that 'supports' the intentional activity of agents or 'resists' it. In its turn, collective agents, including the political organization, act intentionally and rationally. They can act in agreement with the social subject and realize mass aspirations, but may conflict with the society and try to impose its own will on the society, using social power.

\section{The Interaction between Political Agent and Social Subject}

Elsewhere I have argued (Dobrolyubov 2009, 2012b, 2020) that the process of extension of the political structure and then the unification of society in each dimensional format passes through two main steps (phases) - administrative and universal.

The Administrative Phase (A-phase) begins when one of competing entity subordinates (conquests, merges, and absorbs) others and unites them into a single political structure (polity, empire, state, etc.). Whether this would be a coercive or voluntary integration (Carneiro 2012) is not so significant for our model, since the coercion is the dependent variable (Bondarenko 2014). All means of integration, from charismatic leadership to warfare, are forms of social power application, whose use is related mainly to affinity or hostility of competing entities. Over time, the communication through common procedures inevitably leads to convergence of differences, unification of social practices, ideas, values and social identity. In this process the attractiveness of integrative ideas and values appears crucial.

The Universal Phase (U-phase) begins when an extended political association becomes a single society - a collective subject. The integrity at this phase is based on common social consciousness, common MS identity and social value system in which the value of that particular society is the top priority. At this phase the extended political organization is legitimized by a common ideology spread to mass consciousness, which includes the ideas of reciprocity of authority and population (for more details see Appendix 1 at https://www.sociostudies.org/ journal/articles/2856875/). If this does not happen then the polity simply breaks up since 'no political regime can survive for a long time based on coercion exclusively or even primarily' (Bondarenko 2014: 225). The solidarity of society at the U-phase transforms political structure of the given scale from fragile to sustainable one.

Shifting from the A-phase to the U-phase implies a transfer of society's self-consciousness, self-sufficiency, and solidarity from a traditional social identity to an identity of a broader scale, which becomes the new MS identity. It is accompanied by crisis of traditional identity, 
values and solidarity, which provokes the whole spectrum of group conflicts - societal, ethnic, and religious, etc. There is also arising conflict between the new (wide) and the old (narrow) elites, which Vilfredo Pareto described as the degeneration and 'circulation of elite' (Pareto 1935). The resolution of these conflicts is the marker of the transition to the U-phase.

The solidarity of society reveals opportunities for mitigating its administrative rigidity, and allows the political system to rely directly on society members. This allows society to release the civil and economic activity of individuals, to develop self-governing, to accelerate the growth of production, trade, etc., but also accelerates social stratification.

We also introduce two supplementary phases that precede and complete the two major stages. The Preliminary Phase (P-phase) is necessary because there is always a certain period before political unification happens at the A-phase. This period begins when polities first encounter with each other and start to interact and compete. The Final Phase (F-phase) is a phase of solidarity dissolution, which is usually hidden in the Universal phase of a society of wider scale, since a society of a narrow scale has to dissolve its MS identity within broader political boundaries. ${ }^{8}$

The pattern of polity-society growth. The political organization of consolidated society gains the ability to compete in a wider surrounding and takes the next step of political extension. Thus, the A-phase of the new wider society coincides with the U-phase of the previous traditional one; and the two-phase cycle repeats within new frameworks. The cycles of societies at different scales are synchronized due to such coincidence of phases. The step-wise expansion of the polity and the subsequent universalization of its society may be defined as the genesis of a socio-political system.

If we apply this rather abstract theoretical schema to real societies (Fig. 1) which expand irregularly at first glance, then basing on the signs of periodic crises and consolidations of societies we can more or less clearly distinguish the phases of their extension (Dobrolyubov $2009,2012 \mathrm{~b}$ ). The duration of A- and U-phases in many cases turned out to be about 250 years. 


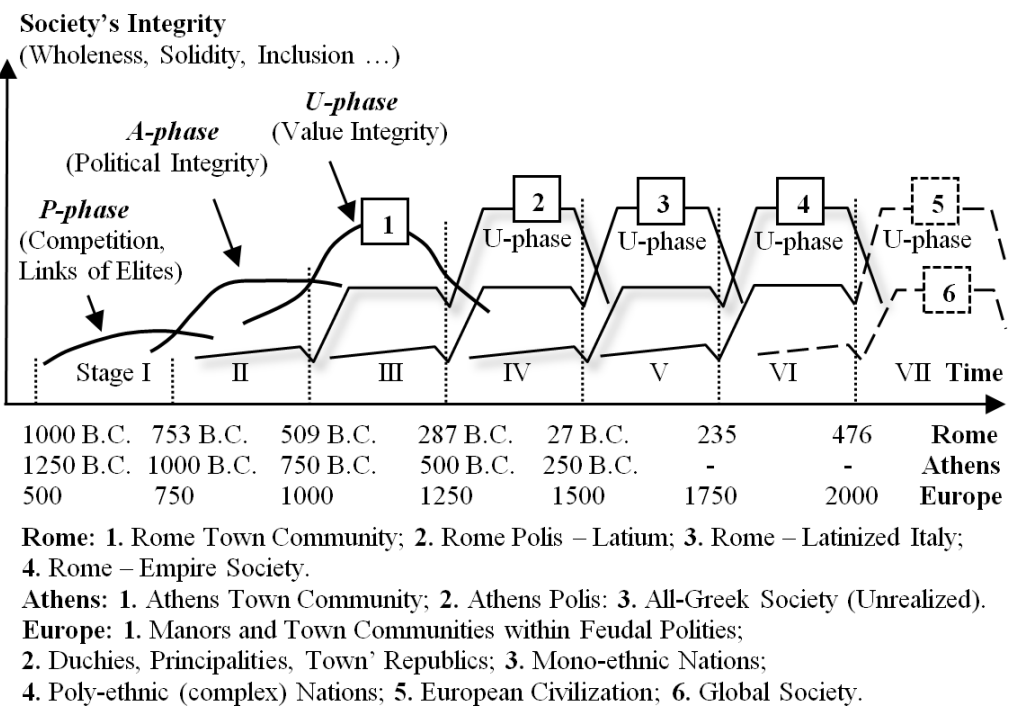

Fig.1. Pattern of society's integrity in the civilizational cycle of sociogenesis

This pattern is not a deterministic law of growth; it is rather a typical two-parameter (polity-society) growth chart of successful societies. There is no law-like cause of political centralization in each case. Political success is always agential, subjective and situational. It is a result of competitive process as indicated by many researchers (Blanton and Fargher 2009; Bondarenko 2014; Grinin 2011b). Some polities do not even strive to expand and subordinate others, while others are eager to do this. The more successful, powerful or lucky polities may expand by steps and then be universalized within broader dimensional niches; and this may happen within similar time frames.

If the next step in the polity growth does not occur, this does not prevent decline of its traditional MS identity. A society falls into an identity crisis and becomes an easy victim for others. The prosperity period for many large ancient polities, for example, Akkad (23162137 BCE), Assyria (1353-1000 BCE), and other lasted for just one phase of the pronounced MS identity (200-300 years). ${ }^{9}$

The duration of the phase is determined by the life cycle of perception of we-they boundary (i.e., recognition of one's own society) and not by the flexibility or inertia of culture. The rise and dissolution of MS identity occurs through a sequence of slight changes of one's own society perception in each new generation; it requires several 
generations. In fact, I cannot give a satisfactory explanation for the stability of such phase duration; and for now, I take it as a natural socio-structural constant $\left(t_{\text {phase }}=\right.$ Const $=250$ years $)$.

\section{Dimensional Format of Society}

The above-presented diagram (Fig. 1) does not correspond directly with the conventional evolutionary typology: band - tribe - chiefdom - state (Sahlins and Service 1960) and its later rconsiderations and corrections (Service 1975; Berezkin 1995; Kradin 2008; Grinin 2011a; Grinin, Korotayev 2011) or more general typology proposed by Grinin and Korotayev: band - settlement - medium complexity society - complex society - early state (Grinin, Korotayev 2011), although their conform with our model.

The model considers the dynamics of a different nature, which is expressed in the societies' passing through dimensional rather than evolutional typology. One may distinguish the following dimensional formats that are actually more suitable for the urbanistic line of civilizations growth: urban, polis, territorial, national, civilizational, and finally global, the latter being rather hypothetical for now (Dobrolyubov 2012b, 2020). These formats correlate, although not rigidly, only with stadial societal formats (Claessen 2002). ${ }^{10}$

The dimensional format in our model is only a size type reflecting a certain level of internal heterogeneity (societal, ethnic, religious, cultural, etc.) that can be leveled out within the framework of a single political entity. Territorial format can be associated with mono-ethnic social entity, national format - with multiethnic entity while civilizational format - with a multinational one. All formats are at the same time natural niches and structural attractors formed by natural borders (river valleys, mountains, islands, continents) and also by social divisions (ethnic, cultural, religious...). For example, the valley of Attica is a niche attractor of a polis format, the Apennine or Iberian Peninsulas are niche attractors of a national format; European continent is a niche attractor of the civilization format. Naturally, Earth is a niche attractor of the global state and society.

\section{Evolutionary Limitations of Sociogenesis}

In order to subordinate and integrate a more diverse society into a broader format, there is needed a higher level of material development (productivity, communication and transport technologies, weapons, etc.) 
and also a more developed consciousness (knowledge, ideologies, religious, universality of values, etc.). We can define them as the material and ideological (intellective, mental) evolutionary prerequisites. For example, Rome in the imperial format was in dire need of monotheistic religion as a supra-ethnic, supra-cultural, more universal and individual oriented (humanistic) ideology in order to universalize its diversity.

Polity at a certain point of its expansion makes an attempt to universalize an overly diverse society for the existing material and ideological evolutionary limitations. If this process remains uncompleted people lose their traditional MS identity and collective solidarity and at the same time they are unable to obtain a wider one; so the political system of this format collapses (e.g., the Roman Empire). ${ }^{11}$

One may also distinguish pristine sociogenesis and secondary cycles of recurrent typical sociogenesis (for more details see Appendix 2 at https://www.sociostudies.org/journal/articles/2856875/).

\section{Application of the Model}

We may use the presented model as a tool for evolutionary conceptualization (Dobrolyubov 2020), but also may apply it to particular societies. If we manage to identify this pattern or at least its part in the chain of historical transformations of a society, we can better explain the past, as well as extrapolate this pattern and forecast the time and nature of subsequent crises in terms of phases of collective identity. Note that the model cannot predict successful or unsuccessful resolution of these crises.

Ancient Rome gave us an ideal type of sociogenesis (see Fig. 1). The political organization and single universal society grew up here step by step (Dobrolyubov 2009). At the first glance, the beginning of the process in Europe (Ibid.) looked different, although actually it followed the same pattern. Although large political entities appeared here at the initial stages, for example, barbarian kingdoms, Carolingian Empire, Kievan Rus, Holy Roman Empire, but these polities were superstructures over smaller social subjects that were self-sufficient and had an isolated subsistence economy and local lords' governance, justice, taxation, etc. Therefore, large fragile polities disintegrated and launched the period of feudal fragmentation. This period ended with the strengthening of medium-size polities: duchies, principalities, and town republic (polis format). Then the process of state centralization began (territorial format), then absolute monarchies appeared, and later complex nations and multinational empires were formed. Today the continuing trend towards enlargement of social format is manifested in the European integration and more broadly - in globalization. 
The peculiarity of Europe is that here we can distinguish two types of nations: mono-ethnic nations, for example, Scotland, England, Poland (Stage V in Fig. 1), which in our scheme correspond to the territorial (ethnic) format, and the integrated complex poly-ethnic nations, most of which appeared as informal societies only at the next stage, for example, Britain, France, Spain, Germany, and Italy (Stage VI in Fig. 1). The model shows that today Europe has come to a point where it will either move further towards a wider civilizational MS identity within a single European state-society, or, like the Roman Empire, will stagnate at the current stage, which may lead both to a fatal loss of national solidarities, and to the failure to acquire a wider one. Without base solidarity, Europe becomes vulnerable to new migrations and, finally, may come to an organizational collapse.

Russia has a noticeable parallel with this sequence of dimensional formats (Dobrolyubov 2009, 2012a), so it is useful to consider it to better understand the pan-European and even global collision.

\section{MODEL APPLICATION TO THE CASES OF ANCIENT RUS} AND RUSSIA

\section{Ancient Rus Sociogenesis}

The beginning of the Ancient Rus sociogenesis is beyond our historic vision. The timing and the character of the Eastern Slavic resettlement and dating of emergence of the first towns is unclear. We can base our sociogenesis scheme (Fig. 2) for sure only on the historically evident transformations. There were three key structural transformations in Ancient Rus. The first one is the subordination of local entities to one center in Kiev at the end of the ninth century; the next one is the fragmentation of this all-Rus polity in the first half of the twelfth century; the third apparent transformation is national centralization in the fifteenth century that historians customarily refer to as the Moscow period. The starting point of sociogenesis in this scheme was obtained by the hypothetical extrapolation of 250-year long P-phase to the past.

So, the dating of the phases is approximate and conditional, because the society's genesis is a slow rise and then a decay of group identity and solidarity. We can trace this process only indirectly through the society's successes or defeats, social crises, disintegration of political entities or formation of new ones. 


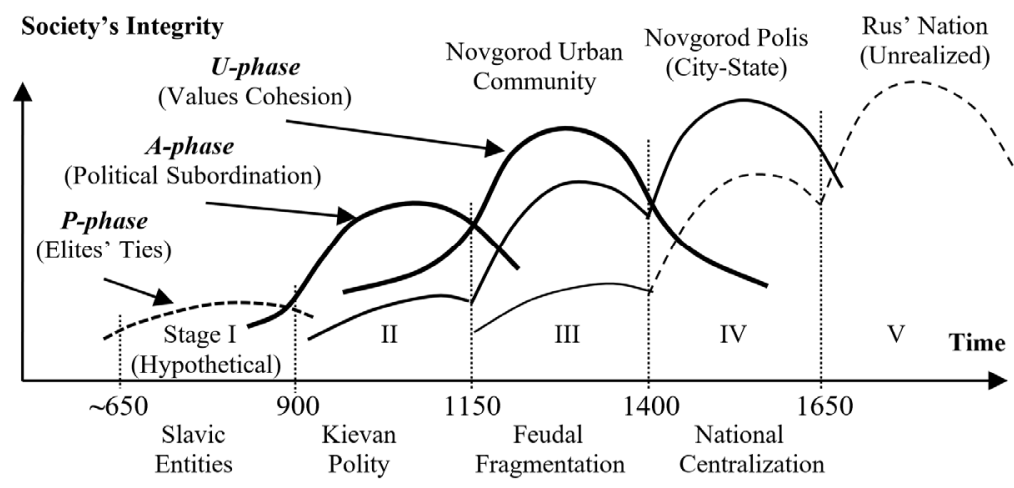

Fig. 2. Diagram of Early Rus sociogenesis (by the example of Novgorod)

Despite the fact that the initial period (900-1150) is characterized by the emergence of a large polity, the actual societal process took place on a smaller scale. It was the period of wide-scale emergence of towns and urban communities. At the next stage (1150-1400) strong independent principalities would grow around them, which then entered the struggle for national centralization (1400-1650). (The reader can find a more detailed description of this process in Appendix 3 at https://www.sociostudies.org/journal/articles/2856875/.)

The Mongol invasion (1237-1240) actually interrupted the allRus national genesis. By the mid-fourteenth century, the Ancient Rus ethno-cultural field was broken up, and its parts were included into different administrative polities of complex-national scale (Golden Horde, Lithuania and later Poland). If not for that, single ethnic nation would have emerged in Ancient Rus ethno-cultural niche, and not three nations (Russian, Ukrainian and Belarusian) which exist now. This would have happened within the boundaries of the centralized state, no matter what its center would have been - Kiev, Vilna or Moscow. Since the all-Rus nation did not pass the A-phase of its formation and did not emerged, we should consider the further genesis of the Russian nation as different from the Ukrainian and Belarusian; although the processes that had taken place before the Mongol invasion did not predetermine such separation.

\section{Russian Sociogenesis}

Russian sociogenesis reproduces the sequence of transformations from a town community into the Grand Duchy of Moscow and then comes 
to the formation of mono-ethnic and later poly-ethnic Russian nation (Fig. 3). The English adjective Russian does not reflect differences in mono-ethnic and poly-ethnic identities and is used to translate two different Russian words. The adjective russkiy (русский) refers to the Russian ethnical identity, while adjective rossiyskiy (российский) refers to the poly-ethnic modern Russian identity. Rossiyskiy is an equivalent of the American political identity which is not ethnical one. Hereafter, for clarity, I will use terms mono-ethnic Russian and polyethnic Russian for these different Russian terms.

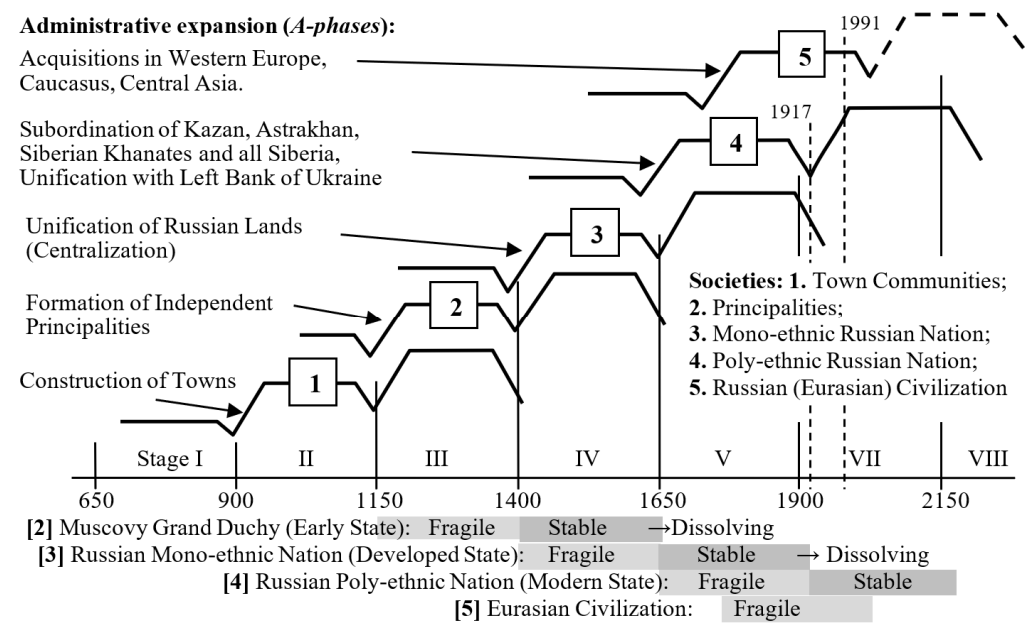

Fig. 3. Russian sociogenesis

Urban communities in the Rus north-east [1] (see Fig. 3). The P-phase began with the Slavs penetration into that region, and the A-phase with the formation of towns. The indicators for emergence of towns are the first references in chronicles; they are indirect and outdated. For Vladimir it is 990, for Yaroslavl - 1010, Ryazan - 1095, Tver 1135 , Moscow - 1147, etc. The U-phase $(1150-1400)$ is a period of strengthening of the towns.

Muscovy [2]. The strong collective identity of town communities allowed local princes to project their power onto the town's surroundings, although at the first glance, this process looks like a fragmentation of larger fragile polities. The period (from 1150 to 1400) was the A-phase of the formation of entities of the polis format that is related with the origin of separate principalities as distinct administrative polities: 
Vladimir (1157), Ryazan (the 1160s), Yaroslavl (1218), Tver - 1246, Moscow (1246), etc.

The U-phase (1400-1650) of the polis-scale entities is manifested in social consolidation and political strengthening of major principalities and exacerbates their competition. At that period Muscovy obtained a self-sufficient Moscow identity, ideology of patriotism and became the most successful among other Grand Duchies.

Russian mono-ethnic nation [3]. This polity of territorial format is commonly called Velikorossiya (Great Russia). The P-phase (11501400) of this format begins with emergence of Grand Duchies as administrative entities which started to compete with each other. The nation was composed by the Slavic and assimilated Finnish population living in territories that later came to be in the Horde part of Ancient Rus and then in the Moscow centralized state. The genetic studies have shown that the Finnish component even prevails over Slavic in the northern part of the modern ethnic Russians (Balanovsky et al. 2008).

The A-phase (lasting from 1400 to 1650) began with the dramatic expansion of the Muscovy polity beyond the possessions of Moscow principality. This process proceeded most actively from 1366 to 1479 . It started as an expansion of the Moscow prince's feudal inheritance, but very quickly it transformed into gathering of the Russian lands. The size of the Muscovy territory reached a national scale; its political system acquired elements of statehood, for example, there emerged bureaucratic ministries - Prikaz (administrative office), first mentioned in chronicles in 1512. However, Muscovy remained an administrative entity until the seventeenth century. Its administrative nature can be deduced from the fact how Assemblies of the Lands (Zemsky Sobors) were formed. Formally, the Sobors (from 1549) were councils of all the lands but consisted of Moscow high nobility (boyars) who had fiefdoms in those lands and Moscow clergy representing the local eparchies. Sobors were rarely complemented by Moscow gentry and burghers (Klyuchevsky 1911). The Novgorod elite made a few attempts to leave this formal entity; the last one happened during the Smuta period (the Time of Troubles).

The transition to the national U-phase (1650-1900) was associated with the transformation of Muscovy's social identity and solidarity into the Russian one. This transition took more than a hundred years and was accompanied by a long series of crises that began with the Oprichnina (1565-72), culminated in the Time of Troubles (Smuta 1604-13) and continued through Schism (Raskol of the 1650-60s) until the reign of Peter the Great (soldier riots of 1682 and 1698). 
Actually, the boyar elite supported the Great Prince's unifying policy, but the expansion of the polity up to the national format changed the whole set of state objectives and required restructuring of the governance. The state's interest in the concentration of limited resources began to interfere with the economic autonomy of the boyar clans, which they retained from the previous period of feudal suzerainty.

Tsar Ivan IV at the time of the Oprichnina began to repress the most influential boyar clans and exchange their patrimonial lands in order to resettle clans from regions where they historically had an economic and political base. He sought to move the basis of social support of extended Moscow polity from the major regional feudal lords, whose loyalty was personal, voluntary and conditional, to a wider stratum of nobility - the national one, who held lands for the state service and, thus, were unconditionally loyal. Such structural re-formatting of the elites recurrently occurred in Russia. It may be interpreted as revolutions of service classes (Hellie 2005), or in terms of long modernization cycles (Wisniewski 1997), or as 'secular' structural cycles lasting for 200-300 years (Turchin and Nefedov 2009), etc.

The conflict between the traditional feudal elite and royal power often occurred at the stage of the nation formation. The major lords supported centralization, but they themselves always turned out to be an obstacle to centralized governance. This is one of the reasons for the trend towards absolute monarchy both in Europe and in Russia.

During the Smuta, the Muscovite state actually collapsed in 16061607. The People's Militia of 1612 (Opolchenie) restored the state with the new Romanov dynasty. This Militia was recruited and funded by minor gentry and burgers from provinces. The Muscovy state entered the Smuta crisis being a formal administrative polity but it came out as a more or less informal Russian national society. Its population obtained an all-Russian ethnic identity, national cohesion, and national solidarity. Relying on mono-ethnic Russian unity, the Russian state became strong at this phase and was able to assimilate Siberia, subdue Central Asia, the Caucasus, and even projected its power onto Europe.

The Russian poly-ethnic nation [4]. This nation is similar to complex European nations such as French, British, Spanish, etc. The P-phase (1400-1650) of this nation began when the administrative Russian mono-ethnic polity of the previous format emerged and started interaction with similar neighboring polities.

The A-phase (1650-1900) was the unification of that poly-ethnic environment within one state. This process had begun even before the mono-ethnic Russian MS identity became mature. The subjection of Kazan (1552), Astrakhan (1554) and Siberian (1582) Khanates paved 
the way for a rapid (taking over a hundred years) accession of Siberia. The administrative formation of this nation core was completed after the unification with the left-bank Ukraine in 1654.

The important peculiarity of Russia was its too fast and early state expansion. This would generate a positive feedback: the state's outrunning expansion demanded social rigidity that contributed to further state expansion. Another problem was the peasants' migration from the gentry's estates to new lands. The attempts to keep peasants at estates led to the historically rapid introduction of serfdom (1596-1649).

The Russian absolute monarchy (Samoderzhavie) was established at the end of the seventeenth century. However, absolutism itself is merely a tool of the elite consolidation. It was necessary for the national consolidation, for example, in England, France, and Spain. ${ }^{12}$

Russia at that stage was a multi-ethnic and multi-confessional administrative entity, and the transfer to its $U$-phase (1900-2150) becomes possible only through secularization of the society and dissolution of the Russian ethnic identity as a MS identity. That is why the Russian Revolutions (1905 and 1917) proclaimed the goals of internationalism, cosmopolitism, 'world revolution', the struggle against the Russian church, Russian nationalism, called chauvinism, and to some extent even against Russian culture (about the role of the Russian revolution see Grinin 2018). These goals consolidated the new Soviet multi-ethnic elite.

The Revolution (1917), Civil War (1918-1921), Collectivization (1929-1930), Industrialization (1927-1935) and WW II (1939-1945) gave rise to social and geographic mobility (e.g., Komlosy 2019) and accelerated universalization of the poly-ethnic Russian community. Secularization withdrew cultural barriers between Orthodox, Muslim, Jew, etc. For example, inter-ethnic families accounted up to 17 per cent in the USSR at the eve of its collapse (Susokolov 1987).

The consequence of these crises was the maturation of a new informal multiethnic community. The Soviet propaganda used the term 'Soviet people' to refer to supra-Russian unity, and applied it to the population of the entire Soviet Union. In fact, the informal community was comprised only by that part of the Soviet Union, which corresponds to the territory of Russian State, formed by the midseventeenth century. Within these borders, Russians and other Orthodox and Muslim people (Eastern Ukrainians, Belarusians, Tatars, Bashkirs, Chuvash, etc.) identify this community as their own society. After WWII this community acquired significant informal integrity.

The current borders of the post-Soviet states do not coincide with that informal community. The North Caucasus is the weakest part of Russian state. The local peoples were incorporated into the Russian 
Empire during the Caucasian War (1817-64). They have not yet acquired a common MS identity with the rest of the Russian commonality. Therefore, if we proceed from the necessity of a 250-year phase for ripening of the MS identity, they will be able to form an informal society with the rest of Russia no sooner than in 2070-2100. This requires the overcoming of clan mentality and mutual recognition of the Caucasians and Russians as we, not they. If the Russian state overcomes the crisis of this transition, it will avoid fragility.

On the other hand, the current borders separate some parts of informal Russian poly-ethnic community. Not only Russia with the North Caucasus, but some other new 'national' post-Soviet states are not nations to the full degree. They inevitably become a formal polity for some of its parts. For example, the Ukrainian ethnos is not a single nation because it does not have a common MS identity. In this sense Ukrainian population is divided into three parts with different social identities relevant to their historical experience - Eastern Ukraine (united with Russia in 1654), Central Ukraine (incorporated in Russia as a result of partitions of Poland in 1772-1795) and Western Ukraine (jointed to the rest of Ukraine in 1939-1945). This generates a binary political polarization of Ukraine. The eastern part of the population has the same poly-ethnic social identity with population of Russia. This part perceives itself as a part of a broader commonality than mono-ethnic Ukrainian or mono-ethnic Russian. That is why they are nostalgic for the Soviet supra-ethnic commonality and voted (at least before the current crisis) in favor of allied relations with Russia. The western part does not have supra-ethnic component of identity, but only ethnic identity and voted for nationalistic policy thus anti-Russian one. That difference does not stem from democratic or non-democratic orientation; it only reflects historical differences in social identity. ${ }^{13}$

The formation of the Russian civilizational (Eurasian) community [5] proceeded from an administrative entity in the wars of westernized Russia with Sweden (1703-1721), Turkey (1769-1870) and other countries. In different periods the Eurasian state included Poland, Baltics, Finland, Caucasus and Central Asia.

The formal integrity gave impetus to the emergence of a common social identity, but this process met some obstacles: the Eurasian community is too diverse and the Russian core does not have sufficient social attractiveness in order to lead the process of informal unification, especially of its Eastern European part. The state in this format had no chance to overcome administrative rigidity; each attempt of political liberalization was accompanied by the collapse of administrative structure (in 1917, 1991). 
The Eurasian community also began forming too early, and the period of its formation overlapped with the period of a poly-ethnic nation formation (Stage V in Fig. 3). The ethnic Russian MS identity was ready to dissolve within the poly-ethnic Russian one, but it lost a clear perception of its boundaries and sought to merge with the Eurasian identity. In a sense, the poly-ethic (national) and Eurasian identities 'interfere' with each other and are mixed in individual minds.

The attempt to liberalize the Soviet Union led to collapse of the Eurasian administrative entity. One may notice that the lag between the two crises - Russian (1917) and Eurasian (1991) - roughly corresponds with the lag in the administrative formation of the relevant administrative polities (Fig. 3).

Although the formal structure has collapsed, the informal basis of the Eurasian commonality still exists as long as dissemination of Russian language, culture, mentality, social practices, and traces of common Soviet identity remain. Besides, the Russian consciousness cannot get rid of civilizational feature - the need to be an attractor of integration, which is often called an imperial trait. Incidentally, the European consciousness also has this feature. The nature of tension between Russia and Europe is not inter-national, but civilizational (i.e. integrative). So the civilizational clash between the West and Russia is manifested in every post-Soviet country. The future of the Eurasian community remains open and is conditioned by the ability of Russia to take civilizational leadership. Civilizational conflict will grow along with the consolidation of the pan-European society and its MS identity.

It is obvious that today the Russian society experiences difficulties with the introduction of advanced social practices which would be relevant to its size, heterogeneity and challenges. The model cannot tell us whether the Russian sociogenesis will be interrupted at this stage and merge with the European one, or it will continue as independent and self-sufficient. The suggested model describes only the nature and possible phases of this process. The social outcome is open, and depends on individuals' and collective agents' effort.

\section{NOTES}

${ }^{1}$ Only the world-system analysis (see e.g., Wallerstein 1974; Grinin, Korotayev, and Tausch 2016; Korotayev, Malkov, and Khaltourina 2006b) operates with the size of the system, but of a different nature and much broader than society.

${ }^{2}$ Indeed, an early state may have the polis format, a developed state a territorial format, a modern state - a national format; and a possible single European state, if it emerges, will have a civilizational format. However, all societies pos- 
sess dimensional dynamics, so we can argue that evolutionary types of society are in accordance with the dimensional formats only as a rule or 'in general'.

${ }^{3}$ The theories of collective actions, of social movements, etc. (Olson 1971; Marco at al. 1999) emphasize a voluntary participation and a solidarity of participants, common goals and proactive cooperation of actors. It hides the authority's nature of the group's organized activity. In fact, even dancers in a pair who want to cooperate and achieve a common goal require ones leadership. If both make individual decisions, the pair just stumbles. Cooperation assumes somebody's guidance and subordination; it implies master-slave relations.

${ }^{4}$ An organization may arise even without an explicit goal of further collective actions and simply out of leader's desire for domination, as for example, in kids' gangs, in family, in soldier barracks, among the elite, etc. For this, leaders need only desire for prestige, superiority, manipulating other people or exercising power over them. However, in fact, the majority of organizations arise for the sake of achieving the pronounced goals, e.g., settlement protection, irrigation, worshipping, executing rituals, trade, raids for booty and so on.

${ }^{5}$ In fact, the action/function duality simply means that the political organization (and state) is a more complex phenomenon than just an acting agent, as we consider it in our model.

${ }^{6}$ The issue of the statehood origin, considered by the early state theory, is a matter of the maturity and separateness of this authority organization and, above all, the emergence of a professional apparatus of power (Grinin 2008). The 'professionalization of administrators' is an exclusive feature of the state (Bondarenko 2014: 222).

${ }^{7}$ However, Durkheim related collective consciousness mainly to traditional society that ensures the 'mechanical' solidarity through rigid traditional institutions (family, social stratum, lifestyle, etc.); while modern society, giving an individual independence from these institutions, ensures 'organic' solidarity. It is assumed that in modern society there is no collective consciousness, but only free and unique individuals.

${ }^{8}$ One may note that already medieval authors included the concept of group solidarity in their cyclic models, although they attributed it to ruling elites (i.e., to collective agents in our terms), and not to society itself, since they never recognized the subject in society. For example, the Arab scholar of the fourteenth century, Ibn Khaldun (Ibn Khaldūn 1958), introduced the concept of asabiyah as group cohesion, but he attributed it to clan groups, therefore, there is a hierarchy and concurrence of different asabiyah in society. It is more like corporative solidarity rather than societal one based on common social identity. Accordingly, he linked degeneration of the ruling dynasty asabiyah with other reasons - with the desire for luxury, a monopoly on power, weakening of civilization, etc. This type of organizations' solidarity certainly exists and can, indeed, determine the rise and fall of various power structures of rigid type, e.g. the rise and fall of the Soviet communist nomenclature, the degeneration of Russian business dynasties of the nineteenth century, etc. They indeed degraded in the third generation of leaders.

${ }^{9}$ If societies were able to take the next step in sociogenesis, then period of prosperity stretched into two phases (500-600 years), for example, the Old Kingdom of Egypt (2686-2181 bce), New Kingdom of Egypt (1549-1069 bce), and etc. The most successful societies go through the full cycle of civilizational sociogenesis, lasting up to 1500 years or more, e.g. Rome, Maya, China and Europe. 
${ }^{10}$ For instance, the urban dimensional format can be associated with a complex chiefdom, polis format with early state and so on. However, our model does not address the issue of whether society has reached the stage of the ES in the polis format or not. We can only assume that if this did not happen, then in evolutionary terms the society is simply not ready for social integration of a polis format, and even more so of a territorial format. This polity will always remain chimeric, fragile and constantly come apart. The same can be said about the adequacy of the territorial format for a developed state and national format for a modern state.

${ }^{11}$ All strong and over-extended states collapsed. This was often accompanied by the invasion by the surrounding barbarians and by a regress to a more primitive level of technology, culture and social institutions. Nevertheless, technologies and ideologies do not disappear completely; they are used as starting conditions by new civilizations or next generation of the same civilization in their new structural cycle.

${ }^{12}$ Poland demonstrated an opposite case. In the seventeenth century Rzeczpospolita was also a poly-ethnic administrative polity and could move toward a complex nation formation only through the strengthening of the royal power and an absolute monarchy. This task appeared to be unattainable despite the high level of polonization of Ukrainian, Belorussian and Lithuanian elites (Klyuchevsky 1911).

${ }^{13}$ Besides, the urban population of Central and Southern Ukraine speaks Russian and tends to political rather than ethnic Ukrainian identity. That is why the ethnic nationalism of Western Ukraine and the political nationalism of the rest of Ukraine are so clearly distinguished.

\section{REFERENCES}

Balanovsky, O., Rootsi, S., Pshenichnov, A., Kivisild, T., Churnosov, M., Evseeva, I., Pocheshkhova, E., Boldyreva, N., Yankovsky, M., Balanovska, E., and Villems, R. 2008. Two Sources of the Russian Patrilineal Heritage in Their Eurasian Context. The American Journal of Human Genetics 82 (1): 236-250.

Berezkin, Yu. E. 1995. Alternative Models of Middle Range Society. 'Individualistic' Asia vs. 'Collectivistic' America? In Kradin, N. N., and Lynsha, V. A., (eds), Alternative Pathways to Early State (pp. 75-83). Vladivostok: Dal'nauka.

Blanton, R. E., and Fargher, L. F. 2009. Collective Action in the Evolution of Pre-Modern States. Social Evolution and History 8 (2): 133-166.

Bondarenko, D. M. 2008. Kinship, Territoriality and the Early State Lower Limit. Social Evolution and History 7 (1): 19-53.

Bondarenko, D. M. 2014. On the Nature and Features of the (Early) State: An Anthropological Reanalysis. Zeitschrift für Ethnologie 139: 215-232.

Bondarenko, D. M., Grinin, L. E., and Korotayev, A.V. 2002. Alternative Pathways of Social Evolution. Social Evolution and History 1 (1): 54-79.

Carneiro, R. L. 1970. A Theory of the Origin of the State. Science 169: 733-738.

Carneiro, R. L. 2012. The Circumscription Theory: A Clarification, Amplification, and Reformulation. Social Evolution and History 11 (2): 5-30. 
Claessen, H. J. M. 2002. Was the State Inevitable? Social Evolution and History 1 (1): 101-117.

Claessen, H. J. M. 2006. Development in Evolutionism. Social Evolution and History 5 (1): 3-40.

Claessen, H. J. M. 2016. The Emergence of Pristine States. Social Evolution and History 15 (1): 3-57.

Claessen, H. J. M., and Skalník, P. (eds.) 1978. The Early State. The Hague: Mouton.

Claessen, H. J. M., van de Velde, P. and Smith, M. E. (eds.) 1985. Development and Decline: The Evolution of Sociopolitical Organization. South Hadley: Bergin and Garvey.

Diamond, J. 2005. Collapse: How Societies Choose to Fail or Succeed. New York: Viking.

Dobrolyubov, S. V. 2009. Theory of Society's Genesis. Social Evolution and History 8 (1): 221-255.

Dobrolyubov, S. V. 2012a. The Polis, Nation and Civilization Cycles of Russia's Sociogenesis. Mir Rossii 2: 116-143. Original in Russian (Добролюбов С. В. Полисный, национальный и цивилизационный циклы социогенеза российской общности. Мир России 2: 116-143).

Dobrolyubov, S. V. 2012b. Sociogenesis vs. Marx Evolutional Determinism: The Anthropic Mechanism of Social Dynamics. Social Evolution and History 11 (1): 88-123.

Dobrolyubov, S. V. 2012c. Collective Agent and Collective Subject: Some Grounds for Conceptualization. Sotsiologicheskiy Zhurnal 2: 53-79. Original in Russian (Добролюбов С. В. Коллективный агент и коллективный субъект: некоторые основания концептуализации. Социологический журнал 2: 53-79).

Dobrolyubov, S. V. 2013. Mind as a Stage of the Nerve Hierarchy Evolution. In Gririn L. E., Korotayev A. V., and Markov, A. V. (eds.), Evolution of the Earth, Life, Society, Mind (pp. 280-321). Volgograd. Uchitel. Original in Russian (Добролюбов С. В. Сознание как стадия эволюции нервной иерархии. Эволюичи Земли, жизни, общества, разума / Ред. Л. Е. Гринин, А. В. Коротаев, А. В. Марков, с. 280-321. Волгоград: Учитель).

Dobrolyubov, S. V. 2020. The Transition to Global Society as a Singularity of Social Evolution. In Korotayev A., and LePoire, D. (eds.), The 21st Century Singularity and Global Futures. World-Systems Evolution and Global Futures (pp. 535-558). Cham: Springer.

Durkheim, E. 1964. The Division of Labor in Society. New York: Free Press.

Giddens, A. 1984. The Constitution of Society: Outline of the Theory of Structuration. Oxford: Polity Press.

Grinin, L. E. 2008. Early State Developed State, Mature State: The Statehood Evolutionary Sequence. Social Evolution and History 7 (1): 67-81. 
Grinin, L. E. 2011a. Complex Chiefdom: Precursor of the State or Its Analogue? Social Evolution and History 10 (1): 234-275.

Grinin, L. E. 2011b. State and Historical Process. The Epoch of the Statehood Formation: General Context of Social Evolution in the Formation of the State. Moscow: LKI. Original in Russian (Гринин Л. Е. Государство и исторический прочесс. Эпоха формирования государства: Общий контекст социиальной эволюиии при образовании государства. М.: Издательство ЛКИ).

Grinin, L. E. 2018. Revolutions and Historical Process. Journal of Globalization Studies 9 (2): 126-141.

Grinin, L. E., Carneiro, R. L., Bondarenko, D. M., Kradin, N. N., and Korotayev, A. V. (eds.) 2004. The Early State. Its Alternatives and Analogues. Moscow, Volgograd: Uchitel.

Grinin, L. E., and Korotayev, A. V. 2011. Chiefdoms and Their Analogues: Alternatives of Social Evolution at the Societal Level of Medium Cultural Complexity. Social Evolution and History 10 (1): 276-335.

Grinin, L. E., Korotayev, A. V., and Herrmann, P. 2010. Introduction. History and Mathematics: Processes and Models of Global Dynamics. In Grinin, L. E., Korotayev, A. V., and Herrmann, P. (eds.), History \& Mathematics: Processes and Models of Global Dynamics (pp. 5-122). Volgograd: Uchitel Publishing House.

Grinin, L., Korotayev, A. and Tausch, A. 2016. Economic Cycles, Crises, and the Global Periphery. Heidelberg, New York, Dordrecht, London: Springer International Publishing.

Grinin, L., de Munck, V. C., and Korotayev, A. (eds.). 2006. History and Mathematics: Analyzing and Modeling Global Development. Moscow: KomKniga/URSS.

Ibn Khaldūn 'Abd al-Rahman. 1958. The Muqaddimah: An Introduction to History. New York, NY: Pantheon Books (Bollingen Series, 43).

Hellie, R. 2005. The Structure of Russian Imperial History. History and Theory 44: 88-112.

Jung, C. G. 1991. The Archetypes and the Collective Unconscious, $2^{\text {nd }}$ edition, Collected Works of C. G. Jung. London: Routledge.

Klyuchevsky, V. O. 1911. A History of Russia. London, New York: J. M. Dent / E.P. Dutton.

Komlosy, A. 2019. Crises, Long Waves, and World-System Analysis. Journal of Globalization Studies 10 (2): 55-76.

Korotayev, A., Malkov A., and Khaltourina, D. 2006. Introduction to Social Macrodynamics: Compact Macromodel of the World System Growth. Moscow: URSS.

Kradin, N. N. 2008. Early State Theory and the Evolution of Pastoral Nomads. Social Evolution and History 7 (1): 107-130. 
Mannheim, K. 1936. Ideology and Utopia: An Introduction to the Sociology of Knowledge. New York: Harcourt, Brace \&World, Inc.

Marco, G., McAdam, D., and Tilly, C. 1999. How Social Movements Matter. Minneapolis, MN: The Regents of the University of Minnesota.

Maslow, A. 1943. A Theory of Human Motivation. Psychological Review 50: 370-396.

Mead, G. 1934. Mind, Self, and Society. Chicago: University of Chicago Press.

Olson, M. 1971. The Logic of Collective Action. Public Goods and the Theory of Groups.

Pareto, V. 1935. The Mind and Society [Trattato Di Sociologia Generale]. New York: Harcourt, Brace.

Parsons, T. 1971. The System of Modern Societies. Englewood Cliffs, N J: Prentice-Hall.

Sahlins, M. D., and E. Service. 1960. Evolution and Culture. Ann Arbor, Michigan: University of Michigan Press.

Service, E. 1975. Origins of the State and Civilization. New York: W. W. Norton \& Company.

Steward, J. H. 1955. Theory of Culture Change. Urbana: University of Illinois Press.

Susokolov, A. A. 1987. Interethnic Families in USSR. Moscow: Mysl. Original in Russian (Сусоколов А. А. Межнациональные браки в СССР. Москва: Мысль).

Tajfel, H., and Turner, J. C. 1986. The Social Identity Theory of Inter-group Behavior. In Worchel, S., and Austin, L. W. (eds.), Psychology of Intergroup Relations (pp. 7-24). Chicago, IL: Nelson-Hall.

Turchin, P. 2003. Historical Dynamics: Why States Rise and Fall. Princeton, NJ: Princeton University Press.

Turchin, P., Grinin, L., de Munck, V. C., and Korotayev, A. (ed.) 2006. History \& Mathematic. Historical Dynamics and Development of Complex Societies. Moscow: KomKniga.

Turchin, P., and Nefedov, S. 2009. Secular Cycles. Princeton: Princeton University Press.

Weber, M. 1978. Economy and Society. Berkeley: University Of California Press.

White, L. A. 1949. The Science of Culture. New York: Grove.

Wallerstein, I. 1974. The Modern World-System: Capitalist Agriculture and the Origins of the European World-Economy in Sixteenth Century. New York: Academic Press.

Wisniewski, R. V. 1997. Modernization Cycles in the History of Russia. In Theory of foresight and the future of Russia. Materials of the $5^{\text {th }}$ Kondratiev readings. Moscow. 